CONCURSO ESTUdiANTIL DE DISEÑO

\title{
ANHELO: Sistema para la creación de una memoria colectiva en la ciudad
}

\author{
Juan A. Casimiro O., Izamar Gutiérrez A., Alberto \\ Herrera L., Isabel López H.
}

Publicado: 21 Septiembre 2016

\begin{abstract}
Resumen
En muchas ocasiones hemos escuchado a nuestros abuelos contar anécdotas de sus vidas y podemos apreciar como el recordar esos momentos los llena de felicidad. Nuestra propuesta toma esas anécdotas y las guarda para que sean compartidas en el futuro, incrementando de esta manera la memoria colectiva de una región en particular. "Anhelo" lleva a los adultos mayores y a las personas de otras edades en un viaje emotivo de forma que puedan experimentar otra vez eventos de su niñez, sus aventuras escolares, todos esos momentos importantes en sus vidas. Con la ayuda de la tecnología el usuario puede viajar en el tiempo y dejar que sus recuerdos sean compartidos. Este proyecto intenta mejorar la salud emocional de los adultos mayores.
\end{abstract}

Palabras clave: Notificación; Consciente del Contexto; Depresión; Recordatorio; Monitorización.

\section{Introducción}

Muchas veces hemos escuchado a nuestros abuelos hablar de sus anécdotas de vida, incluso podemos apreciar cómo el recordar los alimenta de dicha y felicidad. ¿Qué pasaría si esas anécdotas no se quedarán en solo unas palabras flotantes a lo largo de la inmensidad, si no que tuvieran la oportunidad de mantenerlas vivas más allá de su vida, en la eternidad? Anhelo es lo que trata de lograr, llevar a los adultos mayores en un "viaje" emocional que les permita recordar su infancia, sus aventuras durante la preparatoria, su primer beso, su boda, su primer baile, en fin, hacerlos vivir de nuevo su juventud, con la ayuda de la tecnología ellos podrán "viajar en el tiempo" y dejar sus memorias plasmadas, sus Anhelos de vida.

\section{Misión}

El proyecto consistirá en transportar a través del tiempo a los adultos mayores, para que ellos puedan recordar el Morelia en distintas épocas, principalmente en periodos de tiempo en los que los usuarios han vivido.

Casimiro, JA., Gutiérrez, I., Herrera, A., López, I.

Fac. de Cs. Físico-Matemáticas

Universidad Michoacana de San Nicolás de Hidalgo

Edificio Alfa, Ciudad Universitaria

Morelia, México

Email: junhper1221@gmail.com, izamarg18@gmail.com,

angelus2112@gmail.com, i.lopez.huerta.96@gmail.com
Nuestra misión es poder dar un Anhelo de vida a aquellos adultos mayores que desean dejar una huella para ser recordados. La misión principal es lograr que tengan presente lo mucho que tienen para ofrecernos y lo importantes e interesantes que son sus anécdotas y vivencias así como ayudar a los adultos mayores a compartir sus memorias y con ello dejar un legado histórico y que puedan contarnos todos esos momentos sumamente especiales e importantes que han vivido en los distintos sitios emblemáticos de nuestra bella Morelia. Más allá de hacerlos vivir recopilando su pasado, es también lograr enriquecer más ampliamente la historia de nuestra ciudad a través de sus vivencias.

\section{Objetivo}

El objetivo fundamental es mejorar la salud emocional de los adultos mayores, al ser este uno de los temas fundamentales en el bienestar de las personas de la tercera edad. A través del uso de Google Cardboard [1] y un teléfono inteligente, se transportará al adulto mayor a la Ciudad de Morelia de los 1930's hasta la actualidad, ya que los adultos mayores que habitan la ciudad pertenecen de esa época en adelante, y más aún, los registros fotográficos previos a esa época son escasos. Con la ayuda de nuestro avatar "Elena Athari" ellos podrán recopilar imágenes antiguas y/o actuales de la ciudad, y podrán seleccionar los lugares más emblemáticos para ellos, y si lo anhelan podrán dejar ahí su huella imborrable que podrá ser vista, a través de un nuevo avatar, por nuevos usuarios al llegar a ese destino. Más aún, "Anhelo" también puede ser adaptado con fines turísticos, dado que la ciudad de Morelia, Mich., México está llena de historia y cultura, y con la ayuda de las remembranzas de los adultos mayores, lograremos enriquecer aún más los magníficos pasajes históricos de nuestra ciudad.

\section{Trabajo previo}

La Realidad Virtual (RV) es una tecnología computacional que replica un medio ambiente, real o imaginario, y que simula la presencia física del usuario y un medio ambiente de manera que le permite interactuar con este [5]. La RV supone un avance y está teniendo nuevas aplicaciones en todos los ámbitos, pero es necesario también evaluar su impacto sobre el individuo, con el fin de saber qué efectos tiene esta tecnología sobre los usuarios cuando se utiliza de forma intensiva o cuando se abusa de ella, sobre todo en las aplicaciones lúdicas actuales, cada vez más virtuales o tridimensionales. No sólo el sector de ocio está utilizando la RV, sino que son cada vez más numerosas las 
aplicaciones inmersivas dirigidas a rehabilitación, adquisición de habilidades, tratamientos clínicos, etc.

Aunque es una tecnología que lleva en desarrollo desde hace varias décadas, la disponibilidad a nivel consumidor de soluciones que implementen exitosamente la experiencia de RV. Uno de los proyectos más representativos que se encuentra en el mercado en cuanto a realidad virtual se refiere es Oculus. Oculus permite ser programado con Unity, además de tener sus propias librerías integradas para habilitar la programación para dispositivos móviles y PCs.

Por otro lado, Google ha desarrollado el proyecto de Google Cardboard (GC) como una alternativa de bajo costo para el uso de aplicaciones de realidad virtual utilizando un teléfono inteligente [1]. Cardboard se refiere, en inglés, al cartón de embalaje con el que GC está hecho. GC es en sí una plataforma que incluye tanto la montura hecha en cartón y el software utilizado en teléfono inteligente (usando Android o iOS). En cuanto a la montura, los usuarios de GC pueden crear su propia versión utilizando componentes de bajo costo (las especificaciones han sido publicadas por Google), o comprar uno hecho. El visor se usa colocando un teléfono inteligente dentro del este y mirando a través de los lentes de la montura (Figura 1).

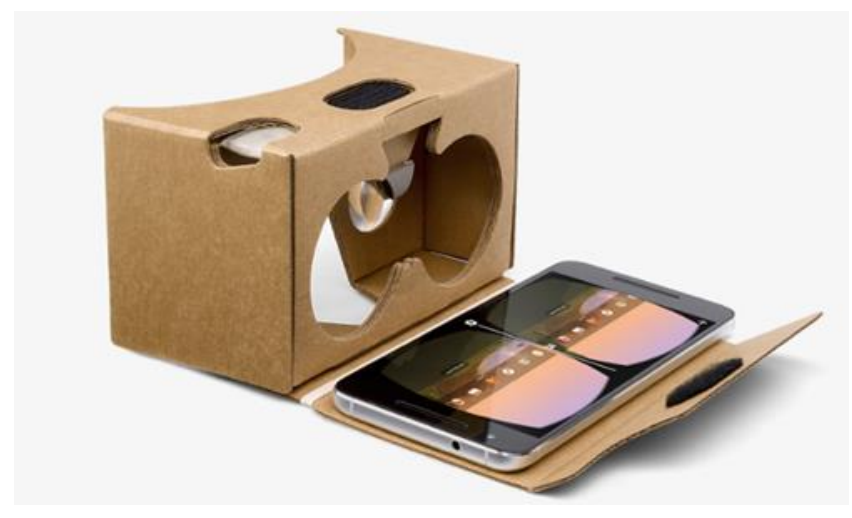

Figura 1. Google Cardboard

Por las caracteristicas de accesibilidad y flexibilidad de GC, seleccionamos dicha plataforma como base de nuestro proyecto. Escencialmente, dentro de GC se visualizará un mapa de Morelia, proporcionado por Google Maps, para que el usuario tenga la opción de viajar al lugar que desee con sólo seleccionarlo en el mapa, así mismo se utilizará Google Street View para visualizar el Morelia actual.

\subsection{Ventajas y desventajas de la realidad virtual}

Son conocidas las ventajas que proporcionan esos entornos virtuales para el aprendizaje, la rehabilitación, el tratamiento psicológico, incluso del uso de videojuegos de RV en diversas áreas de la salud, pero también hay estudios que apuntan hacia unos posibles efectos colaterales [3] generados por la inmersión en RV, a veces denominados ciber-molestias.

Algunos autores hablan de "ciber-molestias" para referirse a los efectos secundarios de la exposición a entornos virtuales que tiene consecuencias para la salud. Estas ciber-molestias incluyen trastornos visuales, desorientación, inestabilidad postural, náuseas, dolor de cabeza, dolores posturales, etc. Para explicarlas se habla de conflictos en la integración sensorial y espacial. Tal como se desarrollan los entornos virtuales, hay una mala adecuación entre el sistema visual, el sistema vestibular y el sistema ambulatorio o postural. El individuo recibe señales de movimiento, pero el sistema vestibular indica que no hay cambio postural y tampoco movimiento. En el momento en que el individuo no puede integrar rápidamente esta información, muy diferente de su mundo habitual (aunque lo simule), se producen molestias y problemas fisiológicos. También la desincronía entre las imágenes, la detección del movimiento en el casco y la integración con el feedback visual correspondiente, causa problemas de orientación y mareos.

A pesar de las grandes ventajas que pueda suponer el uso de la RV, estos estudios indican posibles efectos secundarios, y algunos informan también sobre un efecto adaptativo de esas ciber-molestias.

\section{Metodología}

Anhelo fue desarrollado utilizando técnicas basadas en el concepto de Diseño Centrado en el Usuario. En particular, se realizó una exhaustiva investigación estadística[4] para tener datos recientes sobre las características de la población de adultos mayores en el país y el estado. Posteriormente se realizaron tres visitas de campo a lugares con distintos niveles de atención a adultos mayores. En primera instancia se visitó un asilo de ancianos (Casa de Abuelos "Miguel Hidalgo"), el cual es un lugar donde se da atención permanente a adultos mayores de escasos recursos o en total situación de indefensión. Es un espacio que es administrado por el gobierno municipal. También se visitó una residencia que funciona en base de aportaciones privadas por parte de sus internos, la Residencia de Adultos Mayores "Vasco de Quiroga", en donde se da atención completa a sus residentes dentro de instalaciones altamente especializadas y con excelente atención integral. Finalmente, se visitó la Estancia Diurna del Adulto Mayor (EDAM) en donde atiende a personas mayores de 60 años durante un horario de $8-15 \mathrm{hrs}$. Todas las visitas se realizaron durante el mes de mayo de 2016.

Posteriormente se realizó un diagrama de afinidad para definir las áreas de oportunidad en las que se podría realizar un proyecto concreto. Ahí se estableció que uno de los principales puntos en común entre todos los adultos mayores era el deseo de compartir sus experiencias con los demás, de dejar sus recuerdos de toda la vida para ser aprovechados por otras personas. Otra característica evidente de la población objetivo es la dificultad para movilizarse, por la degradación física que sus cuerpos experimentan al envejecer. Esencialmente, estas fueron las principales motivaciones para Anhelo. Al finalizar los experimentos se realizaron entrevistas a los usuarios de prueba.

\section{Anhelo}

Nuestro Proyecto, Anhelo, consiste de un recorrido virtual por zonas de la ciudad de Morelia que le sean familiars al usuario, en este caso a los Adultos Mayores. El adulto mayor será guiado por una avatar llamada "Elena Athari" (Elena viene del griego "Helena" que significa "Luz brillante" y Athari del purépecha "Atari" que significa "Cazadora"), la cual será la responsable de orientarlo por cualquier lugar que desee el adulto mayor. En cualquier momento el adulto mayor podrá retroalimentar el programa con anécdotas o historias que él quiera compartir a los futuros usuarios dejando así un legado; la historia quedará anclada al lugar donde se encuentre, después, cuando algún otro usuario quiera escuchar la historia esta será contada por un nuevo avatar que representará a la persona que contó la historia, generando así una memoria colectiva a la cual cualquier persona podrá tener acceso.

El proyecto se podrá llevar a cabo con la ayuda de las gafas para realidad virtual de Google, Google Cardboard. Para realizar las pruebas se hará uso de la herramienta "mago de oz" para crear 
el efecto de que el usuario está hablando con el asistente de realidad virtual Elena, está lo guiará por la ciudad con el uso de Google Street View y en cualquier momento que el adulto mayor quiera interactuar con ella, ya sea para contar su historia o hacerle preguntas, sólo tendrá que llamarla y ella acudirá.

\section{Pruebas de usabilidad}

Se realizaron cuatro pruebas, tres con mujeres y una con un hombre; dos de ellas pertenecían a la tercera edad, la otra mujer tiene 45 años y el hombre era un sujeto de 23 años (Figura 2). Se diseñó una actividad basada en la técnica de Mago de Oz, la cual permite identificar la manera en que un usuario interactúa con una interfaz antes de ser totalmente desarrollada, apoyándose en el uso de prototipos de baja fidelidad [2].

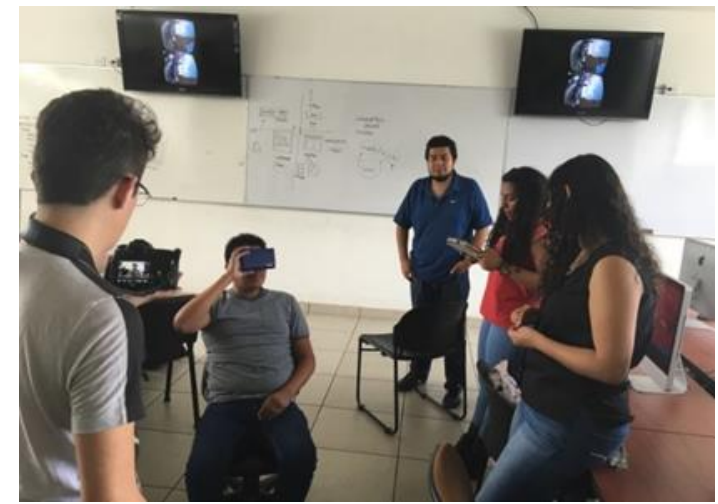

Figura 2. Realización de prueba de usabilidad

La prueba consistió en llevarlos a través de un recorrido virtual por una ruta familiar para ellos, se les dio la tarea de ir de un punto determinado (inicio) a un punto final, para ello usamos un visor de realidad virtual y la aplicación Google Street View. Se estableció una duración de 10 minutos por recorrido, y una duración aproximada de media hora en la totalidad de la prueba. Todas las sesiones de experimentación fueron realizadas en el laboratorio de cómputo de la Facultad de Ciencias FísicoMatemáticas de la Universidad Michoacana de San Nicolás de Hidalgo los días 6 y 7 de julio de 2016. Se utilizó un Google Cardboard, con un iPhone 6s ejecutando la aplicación de Google StreetView. Lo que el usuario veía era replicado en dos monitores conectados a un Apple TV. Todas las sesiones fueron documentadas con la grabación de audio y video.

En la primera prueba, el usuario varón hizo un recorrido entre dos puntos de la ciudad que le eran familiares a él. Nuestro sujeto de prueba no es residente de la ciudad, por lo que se le dio un recorrido entre lugares ampliamente conocidos en el centro histórico. Antes de comenzar el recorrido se les explicó las funcionalidades básicas del hardware, y se les pidió firmar una forma de consentimiento para participar en el experimento (Figura 3). Se les explicó que en todo el recorrido estarían acompañadas por un asistente virtual (Elena), el cual fue creado con el método de Mago de Oz, Elena las guiaba cuando la necesitaban, ella estaba para escuchar sus anécdotas, así como para contarles las historias de los lugares representativos del recorrido (Figura 4).

Dos de los sujetos de prueba eran madre e hija, lo que hizo de la experiencia algo más emotiva y significativa para la señora de la tercera edad que pudo escuchar los recuerdos de su hija, además de dejarnos sus recuerdos. El tercer sujeto de prueba fue elegido de tal manera que pudiera realizar el mismo recorrido de los dos sujetos anteriores, es decir, que este recorrido fuera también familiar para él, pero sin tener ningún vínculo con ellas. (Las tres mujeres vivieron en la misma zona de la ciudad durante parte de sus vidas).

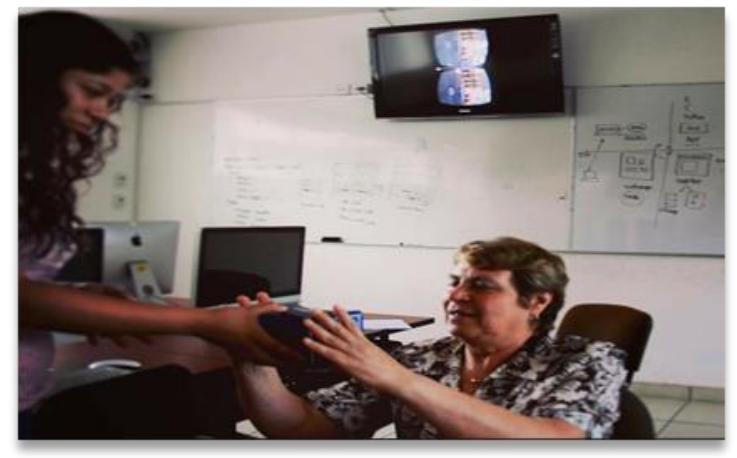

Figura 3. Descripción de la prueba y uso de Google Cardboard

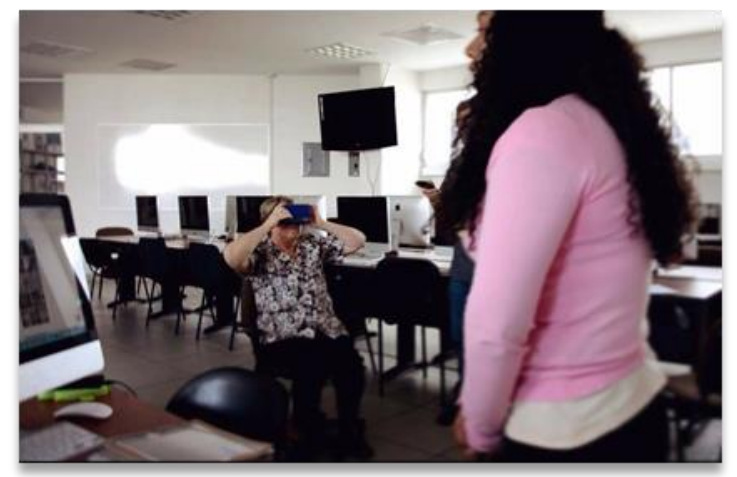

Figura 4. Elena da instrucciones durante el recorrido, y acompaña virtualmente al usuario de prueba

\subsection{Observaciones de los experimentos}

Pudimos constatar que nuestro prototipo funcionó de manera satisfactoria. Observamos también que los sujetos se sentían más seguros al saber que estarían guiados por Elena. El uso del visor de realidad virtual tuvo pequeñas dificultades al inicio, pero una vez que se acostumbraron a este pudieron sentirse confiadas de que esta nueva tecnología era fácil de usar.

Las dificultades fueron dadas por la aplicación de Google Street View, ya que para ellas era complicado en determinados momentos el posicionar la flecha que indica la dirección en la cual quieren avanzar, algunas veces ellas necesitaban levantar la cabeza, para ello Elena los apoyaba diciéndoles cómo colocar la cabeza o para donde voltear, una vez entendido esto todo funcionó mejor, incluso lograron trasladarse sin la ayuda de Elena hasta el final del recorrido. No se les complicó dejar un recuerdo. Solo que olvidaron decir el comando que les indicaba Elena para poder dejarlo "Tengo un recuerdo", en algunos momentos solo decían "Aqui recuerdo...." o al final del recuerdo decían "... es todo" cuando el comando para poder guardar el recuerdo era "Te entrego mi recuerdo".

La experiencia para nosotros como equipo fue muy satisfactoria, ya que pudimos observar cómo impactaba emocionalmente este proyecto a los sujetos, una de ellas lloró en algún punto mientras nos compartía un recuerdo, otro sujeto nos contó cosas muy personales, eso nos demostró que les dimos la confianza para poder hacerlo, la idea de que otras personas pudieran escuchar lo que ellos le decían a Elena los emocionaba mucho. No nos comentaron que sintieran complicaciones como 
mareos, desequilibrio entre otros, tal vez el motivo de tener al sujeto en una silla giratoria pudo evitar estos efectos secundarios.

\section{Conclusiones y trabajo futuro}

Nuestra experiencia con el proyecto fue muy satisfactoria confirmo nuestra teoría que los adultos mayores, si tienen la oportunidad, comparten efusivamente sus recuerdos con los demás. Verlos a ellos inmersos en la experiencia nos enseñó que no le tienen miedo a la tecnología siempre y cuando sientan la seguridad de estar acompañados por alguien, en nuestro caso Elena. Con este proyecto podemos incluir a nuestros adultos mayores en nuestra vida tecnológica.

En un futuro planeamos ampliar el rango de edades de nuestros usuarios vinculando nuestro software a distintas redes sociales de tal manera que cuando realice un recorrido y algunos de sus contactos haya obsequiado un recuerdo se lo notifique de manera que los recuerdos que Elena presente estén ligados personalmente con el usuario.

\section{Agradecimientos}

Agradecemos enormemente la ayuda del personal de la Casa de Abuelos "Miguel Hidalgo", Residencia del Adulto Mayor "Vasco de Quiroga" y la Estancia Diurna del Adulto Mayor, todas en la ciudad de Morelia, Mich. por las facilidades prestadas para la realización de nuestras visitas de estudio.

\section{Referencias}

[1] Coz, D. and Henry, D. 2014. Google Cardboard. (2014). DOI: https://www.google.com/get/cardboard/.

[2] Grill, T., Polacek, O. and Tscheligi, M. 2012. ConWIZ: a tool supporting contextual Wizard of $\mathrm{Oz}$ simulation. In Proceedings of the 11th International Conference on Mobile and Ubiquitous Multimedia (MUM '12). ACM, New York, NY, USA, , Article 21,8 pages. DOI=http://dx.doi.org/10.1145/2406367.2406394

[3] Guerrero, B. and Valero, L. 2013. Efectos secundarios tras el uso de realidad virtual inmersiva en un videojuego, International Journal of Psychology and Psychological Therapy, Universidad de Málaga, España. DOI: http://www.ijpsy.com/volumen13/num2/353/efectossecundarios-tras-el-uso-de-realidad-ES.pdf

[4] INEGI. 2015.“Cuéntame: Información por Entidad, Michoacán”. Instituto Nacional de Estadística Geografía e Informática. México.

DOI:http://cuentame.inegi.org.mx/monografias/informacion/ Mich/Poblacion/default.aspx?tema=ME\&e $=16$

[5] Isaac, J. 2016. "What is Virtual Reality?". completegate.com. DOI:https://www.completegate.com/2016070154/blog/virtua 1-reality-explained\#vrdef 